Note

\section{Synthesis of $N^{\prime}$-(3-Hydroxy-12- methyltridecanoyl)nornicotine}

\author{
Hideyuki K UNO, Makoto SHIBAGAKI, \\ Toshiake MATSUZAKI, ${ }^{*}$ Masashi MIYANO, \\ Norio Yasumatsu, * Hajime Matsushita \\ and Akira KoIWAI \\ Life Science Research Laboratory, \\ Japan Tobacco Inc. \\ * Tobacco Science Research Laboratory, \\ Japan Tobacco Inc., \\ 6-2 Umegaoka, Midori-ku, Yokohama, \\ Midori-ku, Yokohama, \\ Kanagawa 227, Japan
}

Received June 28, 1988

The $N^{\prime}$-acylnornicotines have been isolated from tobacco leaves. ${ }^{(\sim 5)}$ Recently, Zador and Jones described the isolation and biosynthesis of the novel compound, $N^{\prime}$-(3hydroxy-12-methyltridecanoyl)nornicotine (1), in the trichomes of Nicotiana stocktonii. ${ }^{6}$ It is known that 1 was selectively toxic to the larvae of Manduca sexta. ${ }^{\text {?) }}$

In our labaratory, compound 1 was isolated independently from leaf-surface resin of the genus Nicotiana, section Repandae, as one of the main components, and the inhibitory effect on tobacco seed germination was examined. $^{8)}$

The present paper deals with the synthesis of the acylnornicotine. 8-Methylnonyl bromide (2) was prerared by the reaction of 1,6-dibromohexane with 2-methylpropylmagnesium bromide in the presence of dilithium tetrachlorocuprate. ${ }^{9)}$ The reaction of the dianion of methyl acetoacetate $^{10)}$ with 2 gave a ketoester $(3)$ in a $12.9 \%$ yield based on 2 . The desired acylnornicotine was obtained in a $44.1 \%$ yield by the reaction of 3 with nornicotine and subsequent sodium borohydride reduction.

It was elucidated that the synthetic product 1 had two peaks on a gas chromatogram, while the natural product 1 that had been isolated from tobacco leaves had one peak. This shows the existence of two compounds in the synthetic product, and the peak with the longer retention time coincided with that of the natural product. The synthetic product could be assigned as a mixture of diasteromers due to the similarity of their mass spectral data. The configuration of the natural product was presumed to be $S$ at the 2'-position, because it is known that the all naturally occurring tobacco nicotinoids have an $\mathrm{S}$ configuration at 2 -position. The absolute configuration of the natural acylnornicotine (1) will be reported later.
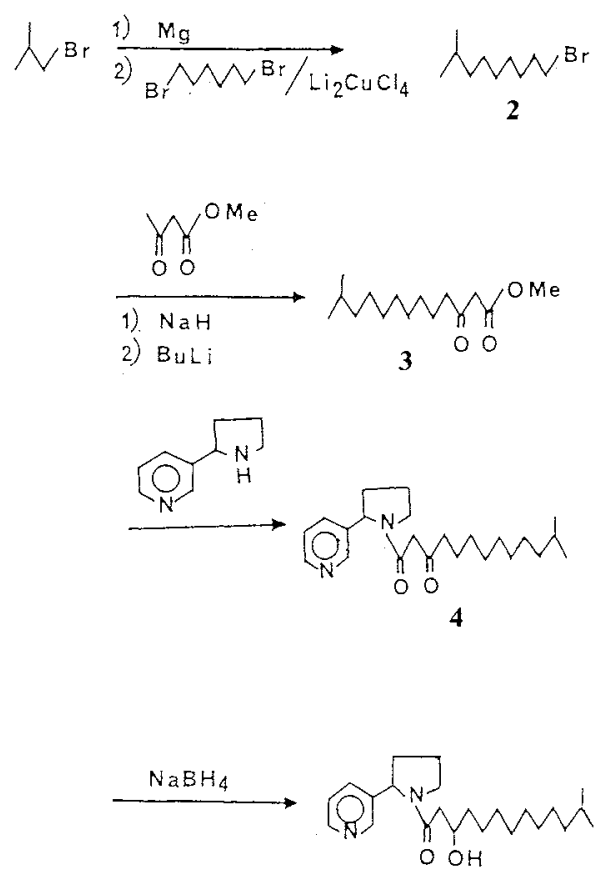

1

\section{Experimental}

${ }^{1} \mathrm{H}-\mathrm{NMR}$ and ${ }^{13} \mathrm{C}-\mathrm{NMR}$ spectra were recorded at $500 \mathrm{MHz}$ on a Bruker AM 500 spectrometer in $\mathrm{CDCl}_{3}$ solution using $\mathrm{Me}_{4} \mathrm{Si}$ as an internal standard. EI mass and high mass spectra were recorded on a Hewlett Packard 5996A mass spectrometer and a JEOL JMS-D300 mass spectrometer, respectively. IR spectra were obtained on a JASCO A-3 spectrophotometer, and GLC data were recorded on a Shimadzu GC-9A gas chromatograph.

A THF solution $(50 \mathrm{ml})$ of 2-methylpropylmagnesium bromide $(8.01 \mathrm{~g})$ was slowly added to a stirred solution of 1,6-dibromohexane $(16.94 \mathrm{~g})$ in THF $(50 \mathrm{ml})$ containing $0.24 \mathrm{~g}$ of $\mathrm{Li}_{2} \mathrm{CuCl}_{4}$. The mixture was stirred for $1 \mathrm{hr}$ and quenched by water, before being extracted with ethyl ether. The extract was dried over anhydrous magnesium sulfate, and 2-methylnonyl bromide (2) was isolated and purified by column chromatography on silica gel with hexane to give $5.23 \mathrm{~g}(47.3 \%$ yield $)$.

Dry THF $(50 \mathrm{ml})$ containing $1.08 \mathrm{~g}$ of sodium hydride (a $50 \%$ mineral oil) was stirred at $0^{\circ} \mathrm{C}$ in a nitrogen atmosphere. Then, $2.32 \mathrm{~g}$ of methyl acetoacetate was added dropwise and the colorless solution was stirred at $0^{\circ} \mathrm{C}$ for $10 \mathrm{~min}$. To this solution was added dropwise $15.2 \mathrm{ml}$ of $1.4 \mathrm{~N} n$-butyllithium in hexane, and the solution was stirred at $0^{\circ} \mathrm{C}$ for $30 \mathrm{~min}$. To the mixture was then added dropwise $5.00 \mathrm{~g}$ of 2 in $5 \mathrm{ml}$ of THF, and the reaction mixture was allowed to slowly warm to room temperature with stirring. Approximately $15 \mathrm{~min}$ after adding 2 , the reaction was quenched with $14 \mathrm{ml}$ of aqueous $\mathrm{HCl}(3.4 \mathrm{~N})$. The mixture 
was extracted with ethyl ether, and the extract was dried over anhydrous magnesium sulfate. 12-Methyl-3-oxotridecanoate (3) was isolated and purified by column chromatography on silica gel with hexane-ethyl acetate $(80: 20)$ to give $1.40 \mathrm{~g}\left(27.3 \%\right.$ yield). ${ }^{1} \mathrm{H}-\mathrm{NMR} \delta$ (ppm): $3.73(\mathrm{~s}, 3 \mathrm{H}), 3.44(\mathrm{~s}, 2 \mathrm{H}), 2.52(\mathrm{t}, J=7.3 \mathrm{~Hz}, 2 \mathrm{H})$, $1.65 \sim 1.10(\mathrm{~m}, 15 \mathrm{H}), 0.87(\mathrm{~d}, J=6.1 \mathrm{~Hz}, 6 \mathrm{H})$.

A solution of $2.10 \mathrm{~g}$ of $d /$-nornicotine and $0.70 \mathrm{~g}$ of methyl 12-methyl-3-oxo-triodecanoate (3) in $30 \mathrm{ml}$ of $x y-$ lene was refluxed for $5 \mathrm{hr}$ with $1 \mathrm{~g}$ of hydrous zirconium oxide, and then cooled. After the mixture had been filtered, the filtrate was concentrated under reduced pressure, and $N^{\prime}$-(12-methyl-3-oxo-tridecanoyl) nornicotine (4) was isolated and purified by column chromatography on silica gel with methanol-ethyl acetate $(20: 80)$ to give $0.55 \mathrm{~g}(53.9 \%$ yield $) .{ }^{1} \mathrm{H}-\mathrm{NMR} \delta(\mathrm{ppm}): 8.60 \sim 8.45(\mathrm{~m}$, $2 \mathrm{H}), 7.45(\mathrm{~m}, 1 \mathrm{H}), 7.41(\mathrm{~m}, 1 \mathrm{H}), 5.21,5.08(\mathrm{dd}, J=3.4$, $4.5 \mathrm{~Hz}, 1 \mathrm{H}), 4.27 \sim 3.30(\mathrm{~m}, 3 \mathrm{H}), 2.63 \sim 1.95(\mathrm{~m}, 5 \mathrm{H})$, $1.70 \sim 1.15(\mathrm{~m}, 17 \mathrm{H}), 0.95(\mathrm{~d}, J=6.8 \mathrm{~Hz}, 6 \mathrm{H})$; IR (neat): $2930,1720,1620,1590 \mathrm{~cm}^{-1}$

To a solution of $0.55 \mathrm{~g}$ of $4 \mathrm{in} 20 \mathrm{ml}$ of 2-propanol was added dropwise $28.0 \mathrm{mg}$ of sodium borohydride. The mixture was stirred for $1 \mathrm{hr}$ at room temperature. After removing the solvent, $20 \mathrm{ml}$ of ethyl ether and $20 \mathrm{ml}$ of water were added. The ethyl ether extract was dried over anhydrous magnesium sulfate and filtered, the product $(0.45 \mathrm{~g})$ being obtained by removing the solvents from the filtrate $(81.8 \%$ yield $)$.

The synthetic and natural products (1) were analyzed by gas chromatography. The column employed was $25 \mathrm{~m}$ of a fused silica capillary, and the column temperature was programmed from 100 to $280^{\circ} \mathrm{C}$ at a rate of $5^{\circ} \mathrm{C} / \mathrm{min}$. The retention times of the peaks ( $\mathrm{min}$ ) were $47.59,47.71$ (synthetic 1) and 47.71 (natural 1). The mass and IR spectra of the synthetic 1 coincided with those of the natural 1. MS (trimethylsilylated deriv. of 1) $\mathrm{m} / \mathrm{z}$ (rel. intensity): $446\left(\mathrm{M}^{+}, 11\right), 432(43), 357(13), 306(20), 292$ (73), $190(20), 175(82), 147(100), 106(27), 73(77), 43(61)$, Found: $m / z$ 374.2963. Calcd. for $\mathrm{C}_{23} \mathrm{H}_{38} \mathrm{O}_{2} \mathrm{~N}_{2}: \mathrm{M}^{+}$, 374.2934. IR (neat): $3400,2930,1620,1590 \mathrm{~cm}^{-1}$.

The ${ }^{1} \mathrm{H}-\mathrm{N} M R$ data show that the synthetic 1 was a mixture of diastereomers, and contains every signal corresponding to that of the natural $1{ }^{1} \mathrm{H}-\mathrm{NMR}$ of synthetic $1 \delta(\mathrm{ppm}): 8.60 \sim 8.45(\mathrm{~m}, 2 \mathrm{H}), 7.47(\mathrm{~m}, 1 \mathrm{H}), 7.28(\mathrm{~m}, 1 \mathrm{H})$, $5.23,5.20,5.02,4.96(\mathrm{dd}, J=3.4,4.5 \mathrm{~Hz}, 1 \mathrm{H}), 4.18 \sim 3.57$ $(\mathrm{m}, 3 \mathrm{H}), 2.61 \sim 2.30(\mathrm{~m}, 3 \mathrm{H}), 2.10 \sim 1.81 \quad(\mathrm{~m}, 4 \mathrm{H})$, $1.65 \sim 1.07(\mathrm{~m}, 17 \mathrm{H}), 0.86(\mathrm{~d}, J=6.8 \mathrm{~Hz}, 6 \mathrm{H}) .{ }^{1} \mathrm{H}-\mathrm{NMR}$ of natural $1 \delta(\mathrm{ppm}): 8.60 \sim 8.45(\mathrm{~m}, 2 \mathrm{H}), 7.47(\mathrm{~m}, 1 \mathrm{H}), 7.28$ $(\mathrm{m}, 1 \mathrm{H}), 5.23,4.96(\mathrm{dd}, J=3.4,4.5 \mathrm{~Hz}, 1 \mathrm{H}), 4.18 \sim 3.57(\mathrm{~m}$, $3 \mathrm{H}), 2.61 \sim 2.30(\mathrm{~m}, 3 \mathrm{H}), 2.10 \sim 1.81(\mathrm{~m}, 4 \mathrm{H}), 1.65 \sim 1.07$ $(\mathrm{m}, 17 \mathrm{H}), 0.86(\mathrm{~d}, J=6.8 \mathrm{~Hz}, 6 \mathrm{H}) \cdot{ }^{13} \mathrm{C}-\mathrm{NMR}$ of synthetic $1 \delta$ (ppm): 172.62, 171.96, 171.88, 149.23, 149.22, 148.47, $148.43,147.64,147.58,147.43,138.45,133.47,133.27$, $133.06,132.99,123.96,123.88,123.55,68.29,68.17,68.15$, $68.00,59.60,59.49,58.75,58.62,47.79,47.02,47.00,41.18$, $41.09,40.99,40.69,39.20,36.70,36.63,36.54,36.51,36.28$, $36.13,33.96,33.91,30.78,30.05,29.81,29.79,28.13,28.11$, $27.56,27.55,25.75,25.73,23.93,22.83,21.73 .{ }^{13} \mathrm{C}-\mathrm{NMR}$ of natural $1 \delta(\mathrm{ppm})$ : 172.62, 171.98, 149.26, 148.46, $147.67,147.49,138.34,133.50,132.99,123.96,123.52$, $68.18,68.06,59.62,58.76,47.79,47.02,41.23,40.72,39.23$, $36.66,36.55,36.32,33.98,29.80,28.15,27.58,25.73$, $23.99,22.84,21.76$.

\section{References}

1) M. Miyano, N. Yasumatsu, H. Matsushita and K. Nishida, Agric. Biol. Chem., 45, 1029 (1981).

2) H. Matsushita, Y. Tsujino, D. Yoshida, A. Saito, T. Kisaki, K. Kato and M. Noguchi, Agric. Biol. Chem., 43, 193 (1979).

3) A. J. N. Bolt, Phytochemistry, 11, 2341 (1972).

4) S. Matsushima, T. Ohsumi and S. Sugawara, Agric. Biol. Chem., 47, 507 (1983).

5) M. Miyano, H. Matsushita, N. Yasumatsu and K. Nishida, Agric. Biol, Chem., 43, 2205 (1979).

6) E. Zador and D. Jones, Plant Physiol., 82, 479 (1986).

7) D. Jones, G. Jones, T. Hagen and E. Creech, Entomol. Exp. Appl., 38, 157 (1985).

8) T. Matsuzaki, M. Miyano, N. Yasumatsu, H. Matsushita and A. Koiwai, Agric. Biol. Chem., 52, 1899 (1988).

9) L. Friedman and A. Shani, J. Am. Chem. Soc., 98, 7101 (1974).

10) S. N. Huckin and L. Weiler, J. Am. Chem. Soc., 96, 1082 (1973). 